\title{
Cognitive Reserve and Lifestyle
}

\author{
Nikolaos Scarmeas and Yaakov Stern \\ Cognitive Neuroscience Division, Department of Neurology, Taub Institute for Research in Alzheimer's Disease \\ and the Aging Brain, and College of Physicians and Surgeons, Columbia University, New York, NY, USA
}

\begin{abstract}
The concept of cognitive reserve (CR) suggests that innate intelligence or aspects of life experience like educational or occupational attainments may supply reserve, in the form of a set of skills or repertoires that allows some people to cope with progressing Alzheimer's disease (AD) pathology better than others. There is epidemiological evidence that lifestyle characterized by engagement in leisure activities of intellectual and social nature is associated with slower cognitive decline in healthy elderly and may reduce the risk of incident dementia. There is also evidence from functional imaging studies that subjects engaging in such leisure activities can clinically tolerate more AD pathology. It is possible that aspects of life experience like engagement in leisure activities may result in functionally more efficient cognitive networks and therefore provide a CR that delays the onset of clinical manifestations of dementia.
\end{abstract}

The CR hypothesis suggests that there are individual differences in the ability to cope with $\mathrm{AD}$ pathology (Stern, 2002). For example, Katzman et al. (1989) described cases of cognitively normal, elderly women who were discovered to have advanced AD pathology in their brains at death. They speculated these women did not express the clinical features of $\mathrm{AD}$ because their brains were larger than average. About $25 \%$ of subjects who during autopsy fulfill pathologic criteria for $\mathrm{AD}$ and were assessed and followed in well-characterized cohorts were clinically intact during life (Ince, 2001). Similarly, most clinicians are aware of the fact that a stroke of a given magnitude can produce profound impairment in 1 patient and while having minimal effect on another. Something must account for the disjunction between the degree of brain damage and its outcome, and the concept of reserve has been proposed to serve this purpose.

Innate intelligence or aspects of life experience like educational or occupational attainment may supply reserve, in the form of a set of skills or repertoires that allows some people to cope with pathology better than others.

Epidemiological data supporting the CR hypothesis include observations that lower educational and occupational attainment is associated with increased risk for incident dementia (Stern et al., 1994). Similarly, lower linguistic ability (as expressed by idea density and grammatical complexity) in early life and childhood mental ability scores are strong predictors of poor cognitive function and dementia in late life (Snowdon et al., 1997; Whalley et al., 2000). This is consistent with the prediction that people with more reserve can cope with advancing $A D$ pathology longer before it is expressed clinically. In addition it has been shown that $\mathrm{AD}$ patients with higher educational and occupational attainment have more rapid cognitive decline than those with lower attainment, consistent with the idea that, at any level of clinical severity, the underlying $\mathrm{AD}$ pathology is more advanced in patients 
with more CR (Stern, Tang, Denaro, \& Mayeux, 1995).

\section{LEISURE ACTIVITIES}

Factors other than IQ, education and occupation might also provide reserve and influence the incidence of AD. It has been theorized that changes in everyday experiences and activity patterns may result in disuse and consequent atrophy of cognitive processes and skills (a view captured in the adage "use it or loose it"; Salthouse, 1991). Taking into account the considerable plasticity of cognitive abilities of older adults, one might predict that deliberate practice of such skills would at least result in stable performance or may even reverse age-related changes. Does the stimulation provided by typical everyday activities facilitate the maintenance and improvement of general cognitive skills via exposure to cognitive training (Hultsch, Hertzog, Small, \& Dixon, 1999)? In other words, could everyday experience affect cognition in a manner that is analogous to physical exercise for musculosceletal and cardiovascular functions?

\section{HEALTHY ADULTS}

Many studies have investigated the association between level of participation in activities and performance on various cognitive tasks in healthy adults (Arbuckle, Gold, \& Andres, 1986; Christensen et al., 1996; Craik, Byrd, \& Swanson, 1987; Erber \& Szuchman, 1996; Hill, Wahlin, Winblad, \& Backman, 1995; Hultsch, Hammer, \& Small, 1993; Luszcz, Bryan, \& Kent, 1997; van Boxtel, Langerak, Houx, \& Jolles, 1996). In general, these studies have reported that there is a positive association between participation in intellectual, social and physical activities and performance on a wide range of cognitive tasks. Nevertheless, the lack of temporal depth of crosssectional studies raises concerns with issues of causal directionality. Does participation in stimulating activities promote cognitive performance or is it that better performing cognitively capable subjects tend to participate in more intellectual, social and physical activities? Longitudinal data can offer a partial resolution of this conundrum.

At least three studies have used structural equation modeling in longitudinal data to address this question. Schooler and Mulatu (2001), reported that initial high levels of intellectual functioning leads to high levels of environmental complexity, which in turn raises the levels of intellectual functioning over a 20-year period. Gold et al. (1995) reported that individuals with higher levels of intellectual ability, education and socioeconomic status are more likely to develop an engaged lifestyle, which in turn contributes to the maintenance of verbal intelligence in later life. Similar observations were reported in a 250 individual sample tested three times over 6 years: intellectually engaging activities seemed to buffer against decline in cognitive functioning (Hultsch et al., 1999). Nevertheless, an alternative model in this study suggested that findings were also consistent with the hypothesis that high-ability individuals lead intellectually active lives until cognitive decline in old age limits their activities.

In another study, individuals with high socioeconomic status who were fully engaged with their environment had the least intellectual decline over 7 and 14 years (Schaie, 1984, 1996). In this study it was widowed women who had never been in the workforce and who exhibited a disengaged lifestyle that exhibited the greatest decline. Finally, Arbuckle, Gold, Andres, Schwartzman, and Chaikelson (1992) reported that participation in intellectual activities was related to maintenance of intellectual performance in a sample of 2 nd World War veterans tested twice over a 40 -year period.

\section{ALZHEIMER'S DISEASE}

Although educational and occupational attainments have been extensively studied, there are very few reports examining the influence of socially and intellectually engaged lifestyle to dementia. One case control study of $\mathrm{AD}$ in Japan (Kondo, Niino, \& Shido, 1994; 60 cases), reported that cases were significantly less active in various use of leisure time, hobbies and psychosocial behaviors. Another case-control study 
examined the presence of nonoccupational activities during midlife in 193 subjects with possible and probable AD (Friedland et al., 2001). When activity patterns were classified into intellectual, passive and physical, cases were less likely to have participated in intellectual activities.

There have been only few prospective longitudinal studies examining the influence of socially and intellectually engaged lifestyle to incident dementia. In a survey sample of 422 elderly subjects the relation of various indicators of socio-economic status to incident dementia was investigated (Bickel \& Cooper, 1994). Only poor quality living accommodations were associated with increased risk of incident dementia, while indicators of social isolation such as low frequency of social contacts within and outside the family circle, low standard of social support and living in single person household did not prove to be significant.

In another cohort, the average minute per day participation in cognitively challenging "complex" (i.e., playing a musical instrument, handicrafts) and basic "simple" (dressing, eating) activities was assessed for 1877 subjects (Zabar, Corrada, Fozard, Costa, \& Kawas, 1996). Regular participation in complex (relative to simple) activities did reduce the risk of developing dementia within 2 years but not within 5,10 or 15 years, suggesting that the effect near the time of diagnosis may reflect changes in activities due to early dementia. Unfortunately, this study has been published only in an abstract form and no details are available.

Another study evaluated social and leisure activity data in 2040 nondemented elderly community residents from Gironde (France) and recorded incident dementia on follow-up visits (Fabrigoule et al., 1995). Traveling, doing odd jobs and knitting were associated with lower risk of incident dementia when occupational status was controlled for. However, the analyses were not controlled for either ethnic group, gender, educational attainment, cerebrovascular risk factors or depressive symptomatology. In addition, for doing odd jobs and knitting, the effect was significant only when subjects who did the activities without difficulty were compared to subjects who did not do them because of deficiencies or disabilities. When the comparison group was subjects who were not engaged in these two activities for other reasons, no significant influence was noted. Therefore, the reasons for engaging in leisure activities, rather than the leisure activities per se, seemed to affect incident dementia in this study.

There have been at least three large prospective studies that demonstrated a clear association between engaged lifestyle and incident dementia. In one of them, social ties (spouse, living arrangements, contacts with friends and relatives, confidant reciprocity and group membership) and participation in productive activities (helping others with daily tasks, paid work and volunteer work) were assessed for 2486 community-dwelling Japanese-American men (free of dementia at baseline) who were followed for 3 years (Balfour, Masaki, White, \& Launer, 2001). Both social engagement and productive activities were significantly and inversely associated with risk of incident dementia. With each additional social tie, the OR for dementia decreased by $16 \%$ and with each additional productive activity, the OR for dementia decreased by $72 \%$ and the effect of the two scales was synergistic. This study is available only in an abstract form.

We recently reported the results of a study involving a total of 1772 nondemented individuals aged 65 years or older, living in Northern Manhattan New York who were identified and followed longitudinally in a community based cohort incidence study for up to 7 years (mean 2.9 years; Scarmeas, Levy, Tang, Manly, \& Stern, 2001). In the initial visit, an interview elicited self-reported participation in a variety of leisure activities of intellectual (reading magazines or newspapers or books, playing cards or games or bingo, going to classes etc.), social (visiting or being visited by friends or relatives, etc.) and even physical (walking for pleasure or excursion, physical conditioning, etc.) nature. Figure 1 presents the cumulative risk for developing dementia in the high and low leisure activity groups, as calculated from survival analysis models. Even when factors like ethnic group, education and occupation were controlled for, subjects with high leisure activity had $38 \%$ less risk of developing dementia. The risk of incident dementia was reduced by approximately 
Age group: 65-74

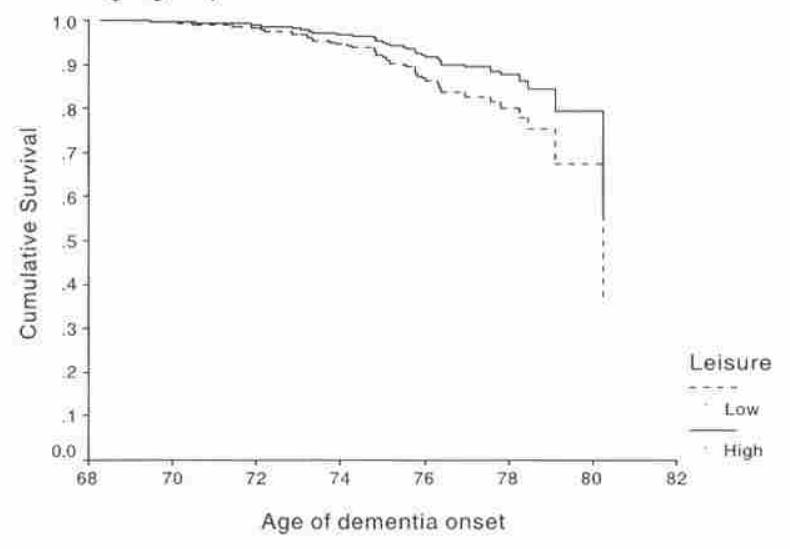

Age group: $75-84$

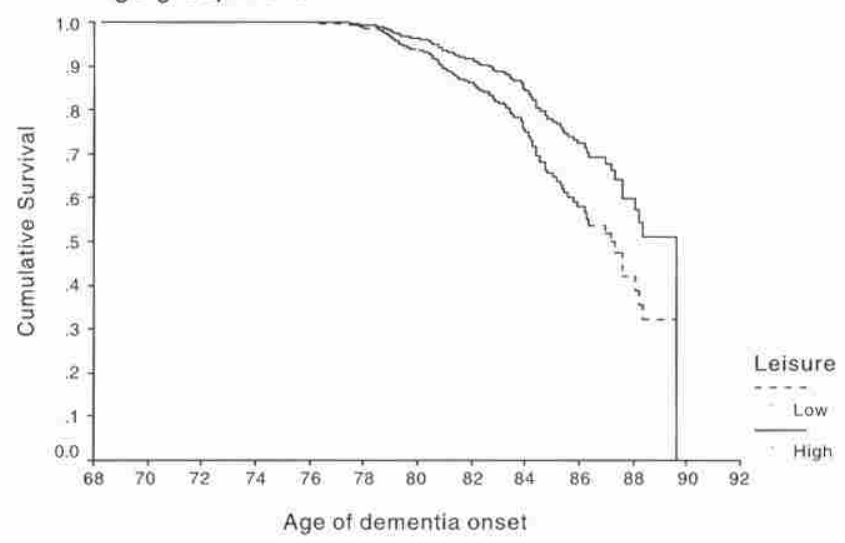

Age group: $85+$

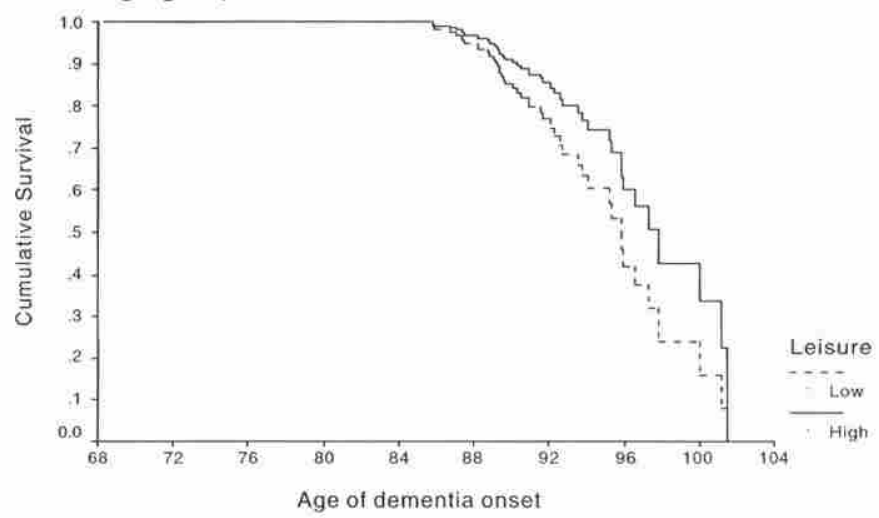

Fig. 1. Survival curve based on Cox analysis comparing cumulative dementia incidence in subjects with high and low leisure activities in three age groups of the cohort (Scarmeas et al., 2001).

$12 \%$ for each additional leisure activity adopted. The effect of leisure activities on incident dementia was still present even when baseline cognitive performance, health limitations interfering with social activities, cerebrovascular disease and depression were considered. 
In another prospective study, frequency of participation in common cognitive activities (i.e., reading a newspaper, magazine, books) was assessed at baseline for 801 elderly Catholic nuns, priests and brothers without dementia (Wilson et al., 2002). During a mean follow-up of 4.5 years, 1-point increase in the cognitive activity score was associated with a $33 \%$ reduction in the risk for AD. Additionally, engagement in cognitive activities was also associated with slower rates of cognitive decline. The results held even when many potential confounders were controlled for and even when subjects with memory impairment at baseline evaluation were excluded from the analyses.

In contrast to previous studies that were investigating risk for incident dementia, another study by the same group has explored the rate of cognitive decline in relation to premorbid reading activity in subjects who had already manifested the disease. In a cohort of 410 persons with $\mathrm{AD}$ followed for a 4-year period higher levels of premorbid reading activity was associated with more rapid decline in the global cognitive and verbal measures (Wilson et al., 2000). Although counterintuitive at first glance, the results are consistent with the hypothesis that intellectual activities may enhance brain's reserve capacity and that at any level of clinical severity, the underlying $\mathrm{AD}$ pathology is more advanced in patients with more CR. Therefore, although subjects with higher CR (compared to ones with lower (R) may manifest dementia symptomatology later in life, they may decline faster after dementia onset. These results for reading activity parallel previous similar ones for education and occupation (Stern, Tang et al., 1995).

\section{IMAGING STUDIES}

Physiologic data from functional imaging studies have served as an indirect affirmation of the reserve hypothesis. Given that the regional correlation between PET cerebral blood flow (CBF) deficits and histologically confirmed postmortem dementia changes is well-established, CBF has been used as a indirect-surrogate measure of disease pathology (lower CBF indicating more advanced pathology). It has been shown that patients with higher educational (Stern, Alexander, Prohovnik, \& Mayeux, 1992), or occupational (Stern, Alexander et al., 1995) attainment, as well as those with higher premorbid IQ (Alexander et al., 1997) have more prominent flow deficits (and hence more pathology) when controlling for clinical severity. These observations support the prediction that individuals with more reserve can tolerate more pathology.

Results from a recent study invoking leisure activities seem to parallel those for education, occupation and IQ. We evaluated leisure (intellectual, social, and physical) activities in 9 patients with early $\mathrm{AD}$ and 16 healthy elderly who underwent brain $\mathrm{H}_{2}{ }^{15} \mathrm{O}$ PET (Scarmeas et al. in press). In a voxel-wise multiple regression analysis which controlled for clinical severity, there was a negative correlation between leisure activity score and CBF. When education, estimates of premorbid IQ or both were added as covariates in the same model, higher leisure activities score was still associated with more prominent $\mathrm{CBF}$ deficits. These results corroborate the hypothesis that at any given level of clinical disease severity, more severe AD pathology exists in the patients with high leisure activities, even when education and IQ are taken into account.

\section{NATURE OF ACTIVITIES}

Although it makes intuitive sense that only cognitively challenging activities might be related to risk for dementia there is also evidence for protection even for noncognitive activities. In our study, when the leisure items were grouped into physical, social and intellectual factors, although the intellectual factor was associated with lowest risk of incident dementia all three factors retained their significant effect in the analyses (Scarmeas et al., 2001).

Epidemiological evidence that physical exercise may delay cognitive impairment is equivocal. While high levels of physical activity were associated with reduced risk of dementia in at least four prospective studies (Laurin, Verreault, Lindsay, MacPherson, \& Rockwood, 2001; Li et al., 1991; Scarmeas et al., 2001; Yoshitake et al., 
1995), no effect of exercise on dementia and cognitive impairment risk was reported from other cohorts (Broe et al., 1998; Wilson et al., 2002). Additionally, there is basic research evidence that environmental enrichment in the form of voluntary wheel running is associated with enhanced neurogenesis in the adult mouse dentate gyrus (van Praag, Kempermann, \& Gage, 1999). It has also been shown that physical activity sustains cerebral blood flow (Rogers, Meyer, \& Mortel, 1990) and it may improve aerobic capacity and cerebral nutrient supply (Dustman et al., 1984; Spirduso, 1980). Therefore, although it is conceivable that physical activity may merely be a nonspecific marker of good health indirectly related to dementia (or even not related to dementia at all), it is also possible that it has a direct physiological association with brain disease.

\section{IS THE ASSOCIATION CAUSAL?}

The association between engaged lifestyle and dementia risk could be either mediated or confounded by abilities like IQ or education. If this is the case then it could be that either IQ or education represent the true causal links with dementia or that subjects with higher IQ or education tend to adopt lifestyles which themselves causally reduce the risk of dementia (such as exercise, diet, etc.). Nevertheless, in studies where education and occupation (Scarmeas et al., 2001) or education and IQ (Scarmeas et al., in press) were controlled for, the association between leisure activities and dementia risk was still there.

It is also possible that both education-occupation-IQ and engagement in stimulating vocational activities are markers of innate capacities. Innate might refer to either genetic background or early life developmental factors or a combination of them. These innate capacities might in turn lead to higher levels of education, more engagement in stimulating vocational activities and lower risk of cognitive decline.

It can also be that there is another yet not identified causal factor-characteristic that confounds or mediates the inverse association between engaged lifestyle and incident dementia.
Another explanation of the findings could be that borderline dementia subjects might have lower leisure activity as a result of early disease. The consequence of such a premise would be that low leisure activity as recorded in epidemiological studies represents a manifestation of early dementia rather than a premorbid risk factor per se. Some studies attempted to partially address this possibility by excluding from the analyses subjects with memory impairment at baseline evaluation or by considering baseline cognitive performance in the analyses (Scarmeas et al., 2001; Wilson et al., 2002). Although the protective effect for leisure activities remained unchanged in these studies, the activities were recorded only a few years before dementia incidence. The longer the interval between assessment of such activities and dementia diagnosis, the more confident one can be about the temporality and causality of the relation. Overall, given the current literature, the scenario of lifestyle being affected by subtle, incipient cerebral disease cannot be completely excluded.

\section{IF THE ASSOCIATION IS TRULY}

\section{CAUSAL, HOW MAY IT TAKE EFFECT?}

Leisure activities may mediate protection via many different ways - various versions of the CR hypothesis.

1. Passive or hardware: Bigger brains tolerate more loss before exhibiting impaired function because of higher number of healthy synapses or neurons resulting in increased number of remaining available ones when a certain percentage of them is affected by a pathologic process (Katzman et al., 1988). Intellectually and socially engaged lifestyle may increase synaptic density in neocortical association cortex (on the basis of stimulation (Katzman, 1993)) which may result in more efficient cognitive function of unaffected neurons that might be able to compensate for loss of function of affected brain areas.

2. Active or software: More efficient use of the same brain networks. Even though the number of neurons or synapses might be the same, enhanced synaptic activity or more efficient 
circuits of synaptic connectivity might exist in subjects exerting more leisure activities.

3. Active or software: More efficient use of alternative brain networks, that is, more efficient ability to shift operations to alternate circuits. As a concrete example, a trained mathematician or somebody with lifelong engagement in mathematical training, might be able to solve a mathematics problem many different ways, while a less experienced individual might have only one possible solution strategy available. The mathematician would have more flexibility in solving the problem if any particular solution strategy was precluded. This built in redundancy would permit greater resilience in the face of brain damage.

Finally, it is conceivable that factors that affect CR may even result in hindering the development of the disease pathology per se. Involvement in challenging avocations during life may even decrease neurodegeneration. This could be mediated via a variety of underlying neurobiological processes such as enhanced chronic neuronal activation associated with increased brain work, increased regional cerebral blood flow, and increased glucose and oxygen metabolism (Friedland, 1993) or even via higher ability for generation of new neurons into adulthood (Eriksson et al., 1998; Johansson, Svensson, Wallstedt, Janson, \& Frisen, 1999; Kukekov et al., 1999) that might help to make up cell loses with cell gains.

The hypothesis of lifestyle modifications affecting brain disease outcome becomes even more exciting in the face of increasing animal research literature about neuronal plasticity and its association with learning, and physically and socially enriched environment. Exposure to an enriched environment, defined as a combination of more opportunities for physical activity, learning and social interaction, produces not only a host of structural and functional changes in the brain but also influences the rate of neurogenesis in adult and senescent animal models (Kempermann, Kuhn, \& Gage, 1997a, 1997b; van Praag et al., 1999).

Aspects of life experience like leisure activities could modify the paradigms used by the brain to mediate a task by making them more efficient or resilient in the face of brain pathology or by recruitment of alternate networks. Interindividual differences in lifestyle may partially mediate the relationship between brain pathology and the clinical manifestation of $\mathrm{AD}$ and engaged lifestyle may supply a reserve that allows an individual to cope longer before AD is clinically expressed.

\section{REFERENCES}

Alexander, G.E., Furey, M.L., Grady, C.L., Pietrini, P., Brady, D.R., Mentis, M.J., \& Schapiro, M.B. (1997). Association of premorbid intellectual function with cerebral metabolism in Alzheimer's disease: Implications for the cognitive reserve hypothesis. American Journal of Psychiatry, 154, 165-172.

Arbuckle, T.Y., Gold, D., \& Andres, D. (1986). Cognitive functioning of older people in relation to social and personality variables. Psychology and Aging, 1, 55-62.

Arbuckle, T.Y., Gold, D.P., Andres, D., Schwartzman, A., \& Chaikelson, J. (1992). The role of psychosocial context, age, and intelligence in memory performance of older men. Psychology and Aging, 7, 25-36.

Balfour, J.L., Masaki, K., White, L.. \& Launer, L.J. (2001). The effect of social engagement and productive activity on incident dementia: The Honolulu Asia Aging Study. Neurology, 56(Suppl.), A239.

Bickel, H., \& Cooper, B. (1994). Incidence and relative risk of dementia in an urban elderly population: Findings of a prospective field study. Psychological Medicine, 24, 179-192.

Broe, G.A., Creasey, H., Jorm, A.F., Bennett, H.P., Casey, B., Waite, L.M., Grayson, D.A., \& Cullen, J. (1998). Health habits and risk of cognitive impairment and dementia in old age: A prospective study on the effects of exercise, smoking and alcohol consumption. Australian and New Zealand Journal of Public Health, 22, 621-623.

Christensen, H., Korten, A., Jorm, A.F., Henderson, A.S., Scott, R., \& Mackinnon, A.J. (1996). Activity levels and cognitive functioning in an elderly community sample. Age and Ageing, 25, 72-80.

Craik, F.I., Byrd, M., \& Swanson, J.M. (1987). Patterns of memory loss in three elderly samples. Psychology and Aging, 2, 79-86.

Dustman, R.E., Ruhling, R.O., Russell, E.M., Shearer, D.E., Bonekat, H.W., Shigeoka, J.W., Wood, J.S., \& Bradford, D.C. (1984). Aerobic exercise training 
and improved neuropsychological function of older individuals. Neurobiology of Aging, 5, 35-42.

Erber, J.T., \& Szuchman, L.T. (1996). Memory performance in relation to age, verbal ability, and activity. Experimental Aging Research, 22, 59-72.

Eriksson, P.S., Perfilieva, E., Bjork-Eriksson, T., Alborn, A.M., Nordborg, C., Peterson, D.A., \& Gage, F.H. (1998). Neurogenesis in the adult human hippocampus. Natural Medicines, 4, 1313-1317.

Fabrigoule, C., Letenneur, L., Dartigues, J.F., Zarrouk, M., Commenges, D., \& Barberger-Gateau, P. (1995). Social and leisure activities and risk of dementia: A prospective longitudinal study. Journal of the American Geriatrics Society, 43, 485-490.

Friedland, R.P. (1993). Epidemiology, education, and the ecology of Alzheimer's disease. Neurology, 43, 246-249.

Friedland, R.P., Fritsch, T., Smyth, K.A., Koss, E., Lerner, A.J., Chen, C.H., Petot, G.J., \& Debanne, S.M. (2001). Patients with Alzheimer's disease have reduced activities in midlife compared with healthy control-group members. Proceedings of the National Academy of Sciences of the United States of America, 98, 3440-3445.

Gold, D.P., Andres, D., Etezadi, J., Arbuckle, T., Schwartzman, A., \& Chaikelson, J. (1995). Structural equation model of intellectual change and continuity and predictors of intelligence in older men [published erratum appears in Psychology and Aging 1998; 13(3): 434]. Psychology and Aging, 10, 294-303.

Hill, R.D., Wahlin, A., Winblad, B., \& Backman, L. (1995). The role of demographic and life style variables in utilizing cognitive support for episodic remembering among very old adults. Journal of Gerontology B Psychological Science and Social Science, 50, 219-227.

Hultsch, D.F., Hammer, M., \& Small, B.J. (1993). Age differences in cognitive performance in later life: Relationships to self-reported health and activity life style. Journal of Gerontology, 48, 1-11.

Hultsch, D.F., Hertzog, C., Small, B.J., \& Dixon, R.A. (1999). Use it or lose it: Engaged lifestyle as a buffer of cognitive decline in aging? Psychology and Aging, 14, 245-263.

Ince, P. (2001). Pathological correlates of late-onset dementia in a multicenter community-based population in England and Wales. Lancet, 357, $169-175$.

Johansson, C.B., Svensson, M., Wallstedt, L., Janson, A.M., \& Frisen, J. (1999). Neural stem cells in the adult human brain. Experimental Cell Research, 253, 733-736.

Katzman, R. (1993). Education and the prevalence of dementia and Alzheimer's disease. Neurology, 43, 13-20.
Katzman, R., Aronson, M., Fuld, P., Kawas, C., Brown, T., Morgenstern, H., Frishman, W., Gidez, L., Eder, H., \& Ooi, W.L. (1989). Development of dementing illnesses in an 80-year-old volunteer cohort. Annals of Neurology, 25, 317-324.

Katzman, R., Terry, R., DeTeresa, R., Brown, T., Davies, P., Fuld, P., Renbing, X., \& Peck, A. (1988). Clinical, pathological, and neurochemical changes in dementia: A subgroup with preserved mental status and numerous neocortical plaques. Annals of Neurology, 23, 138-144.

Kempermann, G., Kuhn, H.G., \& Gage, F.H. (1997a). Genetic influence on neurogenesis in the dentate gyrus of adult mice. Proceedings of the National Academy of Sciences of the United States of America, 94, 10409-10414.

Kempermann, G., Kuhn, H.G., \& Gage, F.H. (1997b). More hippocampal neurons in adult mice living in an enriched environment. Nature, 386, 493-495.

Kondo, K., Niino, M., \& Shido, K. (1994). A casecontrol study of Alzheimer's disease in Japan significance of life-styles. Dementia, 5, 314-326.

Kukekov, V.G., Laywell, E.D., Suslov, O., Davies, K., Scheffler, B., Thomas, L.B., O'Brien, T.F., Kusakabe, M., \& Steindler, D.A. (1999). Multipotent stem/progenitor cells with similar properties arise from two neurogenic regions of adult human brain. Experimental Neurology, 156, 333-344.

Laurin, D., Verreault, R., Lindsay, J., MacPherson, K., \& Rockwood, K. (2001). Physical activity and risk of cognitive impairment and dementia in elderly persons. Archives of Neurology, 58, 498-504.

Li, G., Shen, Y.C., Chen, C.H., Zhau, Y.W., Li, S.R., \& Lu, M. (1991). A three-year follow-up study of agerelated dementia in an urban area of Beijing. Acta Psychiatrica Scandinavica, 83, 99-104.

Luszcz, M.A., Bryan, J., \& Kent, P. (1997), Predicting episodic memory performance of very old men and women: Contributions from age, depression, activity, cognitive ability, and speed. Psychology and Aging, 12, 340-351.

Rogers, R.L., Meyer, J.S., \& Mortel, K.F. (1990). After reaching retirement age physical activity sustains cerebral perfusion and cognition. Journal of the American Geriatrics Society, 38, 123-128.

Salthouse, T. (1991). Theoretical perspectives on cognitive aging. Hillsdale, NJ: L. Erlbaum Associates.

Scarmeas, N., Levy, G., Tang, M., Manly, J., \& Stern, Y. (2001). Influence of leisure activity on the incidence of Alzheimer's disease. Neurology, 57, 2236-2242.

Scarmeas, N., Zarahn, E., Anderson, K.E., Habeck, C., Hilton, J., Flynn, J., Marder, K., Bell, K., Sackeim, H., Van Heertum, R., Moeller, J.R., \& Stern. Y. (2002). Association of life activities with cerebral blood flow in Alzheimer's disease: Implications for 
the cognitive reserve hypothesis. Archives of Neurology, 60, 359-365.

Schaie, K. (1984). Midlife influences upon intellectual functioning in old age. International Journal of Behavioral Development, 7, 463-478.

Schaie, K.W. (1996). Intellectual development in adulthood: The Seattle longitudinal study. New York: Cambridge University Press.

Schooler, C., \& Mulatu, M.S. (2001). The reciprocal effects of leisure time activities and intellectual functioning in older people: A longitudinal analysis. Psychology and Aging, 16, 466-482.

Snowdon, D.A., Greiner, L.H., Mortimer, J.A., Riley, K.P., Greiner, P.A., \& Markesbery, W.R. (1997). Brain infarction and the clinical expression of Alzheimer disease. The Nun Study. Journal of the American Medical Association, 277, 813-817.

Spirduso, W.W. (1980). Physical fitness, aging, and psychomotor speed: A review. Journal of Gerontology, 35, 850-865.

Stern, Y. (2002). What is cognitive reserve? Theory and research application of the reserve concept. Journal of the International Neuropsychological Society, 8 , 448-460.

Stern, Y., Alexander, G.E., Prohovnik, I., \& Mayeux, R. (1992). Inverse relationship between education and parietotemporal perfusion deficit in Alzheimer's disease. Annals of Neurology, 32, 371-375.

Stern, Y., Alexander, G.E., Prohovnik, I., Stricks, L., Link, B., Lennon, M.C., \& Mayeux, R. (1995). Relationship between lifetime occupation and parietal flow: Implications for a reserve against Alzheimer's disease pathology. Neurology, 45, 55-60.

Stern, Y., Gurland, B., Tatemichi, T.K., Tang, M.X., Wilder, D., \& Mayeux, R. (1994). Influence of education and occupation on the incidence of Alzheimer's disease. Journal of the American Medial Association, 271, 1004-1010.
Stern, Y., Tang, M.X., Denaro, J., \& Mayeux, R. (1995). Increased risk of mortality in Alzheimer's disease patients with more advanced educational and occupational attainment. Annals of Neurology, 37, 590-595.

van Boxtel, M.P., Langerak, K., Houx, P.J., \& Jolles, J. (1996). Self-reported physical activity, subjective health, and cognitive performance in older adults. Experimental Aging Research, 22, 363-379.

van Praag, H., Kempermann, G., \& Gage, F.H. (1999). Running increases cell proliferation and neurogenesis in the adult mouse dentate gyrus. Nature Neuroscience, 2, 266-270.

Whalley, L.J., Starr, J.M., Athawes, R., Hunter, D., Pattie, A., \& Deary, I.J. (2000). Childhood mental ability and dementia. Neurology, 55, 1455-1459.

Wilson, R.S., Bennett, D.A., Gilley, D.W., Beckett, L.A., Barnes, L.L., \& Evans, D.A. (2000). Premorbid reading activity and patterns of cognitive decline in alzheimer disease. Archives of Neurology, 57, 1718-1723.

Wilson, R.S., Mendes de Leon, C.F., Barnes, L., Schneider, J.A., Bienias, J.L., Evans, D.A., David, A., \& Bennett, D.A. (2002). Participation in cognitively stimulating activities and risk of incident alzheimer disease. Journal of the American Medical Association, 287, 742-748.

Yoshitake, T., Kiyohara, Y., Kato, I., Ohmura, T., Iwamoto, H., Nakayama, K., Ohmori, S., Nomiyama, K., Kawano, H., \& Ueda, K. (1995). Incidence and risk factors of vascular dementia and Alzheimer's disease in a defined elderly Japanese population: The Hisayama Study. Neurology, 45, 1161-1168.

Zabar, Y., Corrada, M., Fozard, J., Costa, P., \& Kawas, C. (1996). Does frequent participation in cognitively demanding leisure activities reduce the risk of developing dementia? Neurology, 46(Suppl.), A435. 
Copyright $@ 2003$ EBSCO Publishing 